\title{
SABERES PEDAGÓGICOS DO PROFESSOR DE GEOGRAFIA elementos para o desenvolvimento do raciocínio geográfico
}

\author{
Denise Mota Pereira da Silva ${ }^{1}$
}

\begin{abstract}
Resumo: Este trabalho trata das limitações da formação inicial do professor de geografia frente aos desafios da docência no âmbito da educação básica. Fatores como as dicotomias presentes nos cursos de licenciatura, a ausência de uma formação teórico-prática, o fato dos cursos não contemplarem o currículo da educação básica e o contexto de atuação dos futuros professores, qual seja, as escolas de níveis fundamental e médio, constituem obstáculos à formação de competências docentes do professor de geografia. A formação inicial deve proporcionar reflexão teórica prática voltada para a tomada de decisão em face do dinamismo da sala de aula. Neste sentido, os cursos de licenciatura em geografia carecem de integração entre as disciplinas específicas e as pedagógicas. Com vistas a superar o ensino pautado na memorização e promover condições que favoreçam o desenvolvimento do raciocínio geográfico, é preciso uma interlocução entre as disciplinas ao longo da formação inicial, bem como contemplar, nessa interlocução, o currículo prescrito para a geografia na educação básica. Ao se considerar os conteúdos previstos para o ensino fundamental e para o ensino médio, estratégias e metodologias apropriadas a cada um deles, criam-se condições para que se desenvolva o raciocínio geográfico do aluno. Para tanto, foram utilizados os fundamentos teóricos de Freire (2004), Callai (2012), Castellar (2012) Cavalcanti (2012), Tardif (2012) e Vygotsky (2014). A metodologia utilizada foi de base qualitativa, a partir de pesquisa bibliográfica. Os resultados apontaram a ausência de interface entre os cursos de formação e as escolas, dado que contribui para que o professor não esteja suficientemente preparado para os desafios da docência na educação básica.
\end{abstract}

Palavras-chave: Formação de Professores. Educação Básica. Raciocínio Geográfico.

\section{TEACHER'S KNOWLEDGE OF GEOGRAPHY elements for the student's geographic reasoning}

\begin{abstract}
This work discusses the limitations of the initial formation of the Geography teacher regarding the teaching challenges in the scope of basic education. Factors such as the dichotomies of undergraduate courses, the absence of a theoretical-practical training, the fact that the courses do not contemplate the curriculum of basic education and the context in which the future teachers will work, that is, primary and secondary schools, are obstacles to the development of teaching skills of the Geography teacher. The initial training should provide practical and theoretical reflection aimed at decision making in face of the classroom dynamism. In this sense, undergraduate courses in Geography lack integration between the specific disciplines and the pedagogical ones. In order to overcome the teaching practices based on memorization and to promote the needed conditions for the student to develop the geographic reasoning, it is necessary a dialogue between the disciplines throughout the initial formation, as well as to contemplate, in this interlocution, the prescribed curriculum for Geography in basic education. When considering the contents provided for elementary and high school, the strategies and methodologies appropriate to each of them, it is possible to create conditions for
\end{abstract}

\footnotetext{
${ }^{1}$ Doutoranda e Mestre em Geografia pela Universidade de Brasília (UnB) na área de concentração em Gestão Territorial e Ambiental. Professora da Carreira do Magistério Público da Secretaria de Estado de Educação do Distrito Federal - SEEDF. Integra o grupo de pesquisa - Ensino, Aprendizagem e Formação de Professores em Geografia da Universidade de Brasília - GEAF/UnB. E-mail: mota.denise@uol.com.br
} 


\section{REVISTA ELETRÔNICA \\ DA GRADUAÇÃO/PÓS-GRADUAÇÃO EM EDUCAÇÃO UFG/REJ}

the development of the student's geographical reasoning. In this sense, we found our theoretical foundations on Freire (2004), Callai (2012), Castellar (2012), Cavalcanti (2012), Tardif (2012) and Vygotsky (2014). The methodology adopted was the qualitative one, based on bibliographic research. The results pointed out the lack of interface between the undergraduate courses and the schools, which contributes to the teacher not being sufficiently prepared for the challenges of teaching in basic education.

Keywords: Teacher's Formation. Basic Education. Geographical Reasoning.

\section{INTRODUÇÃO}

A formação de professores de geografia no Brasil, em instituições públicas ou privadas, configura-se um desafio no sentido de promover competências docentes que favoreçam a aprendizagem dos estudantes nas etapas dos ensinos fundamental e médio, na qual a grande maioria desses profissionais exercerão sua profissão.

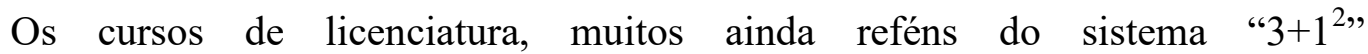
(CAVALCANTI, 2012), continuam ofertando disciplinas que não dialogam entre si. Para Callai (1999), não há sentido na dicotomização entre o bacharel e o licenciado, posto que a função técnica e a função social são aspectos que constituem a formação do profissional em geografia. Os cursos de licenciatura são inspirados em um curso de bacharelado na medida em que priorizam as disciplinas da formação específica, em detrimento daquelas pedagógicas (PEREIRA, 1999). Para Callai (1999, p. 19-20):

A dimensão pedagógica não se resume às disciplinas pedagógicas necessárias à habilitação do professor, mas é a capacidade de se perceber, se reconhecer como educador no interior de um processo de trabalho em que estão envolvidas pessoas e que, em última análise, é a elas, quer dizer, à sociedade que se destina o produto do trabalho.

A autora é enfática ao destacar a função social da formação do professor e da responsabilidade atribuída a este profissional enquanto agente de transformação da realidade, competência não desenvolvida durante a formação inicial, em razão, dentre outros fatores, das dicotomias - geografia física/geografia humana; saber científico/saber pedagógico - presentes nos cursos de licenciatura.

Como consequência da dicotomia entre a formação pedagógica e a específica, as competências docentes do professor de geografia ficam comprometidas. No cotidiano da sala de aula, no entanto, espaço de atuação do professor por excelência, tais

\footnotetext{
${ }^{2}$ Organização curricular dos cursos de licenciatura em que são cursados nos três primeiros anos as disciplinas da parte específica e no último ano, as disciplinas pedagógicas, desvinculadas das primeiras.
} 


\section{REVISTA ELETRÔNICA \\ DA GRADUAÇÃO/PÓS-GRADUAÇÃO EM EDUCAÇÃO UFG/REJ}

\section{TTEERPUS REFLECTIONIS}

ISSN. 1807-9342

Volume 14, N. 2, 2018

competências serão necessárias ao longo do processo de ensinar e aprender geografia. Além disso, todo conhecimento produzido sobre a geografia, na perspectiva da Geografia Escolar, não é apropriado pelos licenciados durante a formação inicial, acarretando inaptidão destes profissionais para a atuação na Educação Básica.

Como teoriza Tardif (2012, p. 286), faz-se necessário que

a formação profissional seja redirecionada para a prática e, por conseguinte, para a escola enquanto lugar de trabalho dos professores. Nessa perspectiva, os saberes (conhecimentos, competências, habilidades etc) transmitidos pelas instituições de formação (universidades, escolas normais, centros profissionais etc) devem ser concebidos e adquiridos em estreita relação com a prática profissional dos professores nas escolas.

A estreita relação dos graduandos com a escola de educação básica deveria ser condição sine qua non para que se conferisse a alguém o diploma de professor. Não obstante, há um verdadeiro abismo entre o universo da instituição formadora e o das escolas. Tal fato está associado, dentre outros condicionantes, ao currículo dos cursos de formação que empurram os estágios para os semestres finais, sem que haja supervisão adequada nem tampouco parceria entre escola e universidade. Cavalcanti (2012, p. 80) defende uma "formação voltada à atividade profissional teórico-prática, que requer reflexão teórica para a tomada de decisões nas tarefas cotidianas".

Neste sentido, a própria concepção do modelo “ $3+1$ ”, ao entender a prática como o momento de aplicação da teoria ao dispor disciplinas denominadas de pedagógicas como os estágios - ao final do curso, não contribui para que o futuro professor esteja preparado para solucionar problemas que surgem no cotidiano da escola. Há que se considerar, ainda, que os profissionais com alta formação e que ingressam nas universidades, especialmente públicas, nem sempre atuaram, anteriormente, como professores da educação básica, fator que dificulta a interlocução dos conteúdos das disciplinas com a dinâmica da escola básica.

Deste modo, o futuro professor não consegue estabelecer um diálogo profícuo entre o embasamento teórico que acumulou durante o curso de licenciatura e a realidade prática da escola. Da mesma forma, não se considera que há uma imensa distância entre o prescrito para as disciplinas "e o que é viável nas condições efetivas de trabalho docente" (PERRENOUD; THURLER, 2002, p. 97). Tais condições de trabalho, 


\section{REVISTA ELETRÔNICA \\ DA GRADUAÇÃO/PÓS-GRADUAÇÃO EM EDUCAÇÃO UFG/REJ}

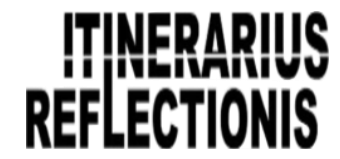

ISSN. 1807-9342

Volume 14, N. 2, 2018

considerando o abandono do poder público no campo da educação em diversas unidades da federação, tornam-se desmotivadoras, especialmente para quem está ingressando na profissão docente. Por isso, é preciso estabelecer contato com a escola por meio dos estágios para que a dinâmica da sala de aula seja vivenciada na medida em que as teorias de aprendizagem e os conhecimentos específicos da geografia sejam estudados e que sirvam de alicerce para a prática docente futura.

\section{A IMPORTÂNCIA DA PRÁTICA NA FORMAÇÃO DO PROFESSOR}

A prática deve ser vivenciada à luz das teorias estudadas, numa simbiose entre o que foi aprendido na universidade e a mobilização de tais conhecimentos na busca de respostas para a complexa e dinâmica realidade da sala de aula. Imbernón (2010) complementa que o professor não deve apenas refletir sobre sua própria prática, mas, na medida em que pensa sobre ela, sua reflexão deve "atravessar as paredes da instituição para analisar todo tipo de interesses subjacentes à educação" (p.42), o que permite compreender o trabalho docente numa perspectiva dialética.

Freire (2004), ao posicionar-se em favor de um constante pensar sobre as ações praticadas em sala de aula, defende que a prática deve estar acompanhada de reflexão crítica:

na formação permanente de professores, o momento fundamental é o da reflexão crítica sobre a prática. É pensando criticamente a prática de hoje ou de ontem que se pode melhorar a próxima prática. O próprio discurso teórico, necessário à reflexão crítica, tem de ser de tal modo concreto que quase se confunda com a prática (FREIRE, 2004, p. 39).

A fusão entre teoria e prática, segundo o autor, requer um processo constante de formação continuada - que deve ser teórica e prática - e que deve acontecer em diferentes espaços de formação, inclusive na própria escola, durante as coordenações pedagógicas e conselhos de classe, na medida em que se buscam respostas para desafios presentes no cotidiano escolar. Do mesmo modo, durante a formação inicial, os cursos devem problematizar situações práticas de ensino-aprendizagem, construindo situações desafiadoras que provoquem reflexões e tomadas de decisões. 


\section{REVISTA ELETRÔNICA \\ DA GRADUAÇÃO/PÓS-GRADUAÇÃO EM EDUCAÇÃO UFG/REJ}

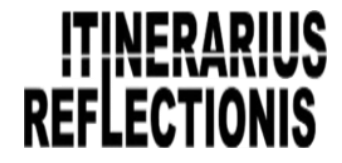

ISSN. 1807-9342

Volume 14, N. 2, 2018

A criticidade sobre a prática defendida por Freire (2004) deve permear a formação do professor desde o início do curso, garantindo-lhe preparação para exercer sua profissão, precavendo-se de, futuramente, deparar-se com uma realidade que se lhe apresente estranha ou para a qual não se sinta capacitado. Neste sentido, Perrenoud e Thurler (2002, p.117) afirmam:

Vários cursos de formação inicial estão baseados mais em uma visão prescritiva da profissão do que em uma análise precisa de sua realidade [...] Logo, para fazer as práticas evoluírem, é importante descrever as condições e as limitações do trabalho real dos professores. Essa é a base de toda estratégia de inovação.

Essa visão prescritiva da realidade é, muitas vezes, romanceada, já que a representação social que se tem dos professores é a de profissionais que possuem vocação para o ofício de ensinar; é como se o fato de se estar imbuído de amor pelos alunos fosse suficiente para executar com competência a profissão. Essa imagem do professor produz uma expectativa no sentido de que bastaria possuir um dom para exercer, com competência, a profissão. Daí a importância e responsabilidade da instituição superior em garantir que, durante a formação, o graduando tenha contato com a dinâmica da escola e da sala de aula, das relações interpessoais que serão estabelecidas com a equipe de profissionais da educação e com os alunos, para que os futuros professores conheçam previamente os desafios da atividade profissional que irão exercer.

A formação inicial, contudo, não é suficiente; deve ser contínua, permanente e ocorrer também nas escolas (CAVALCANTI, 2012). Para que haja aprimoramento da prática docente, o processo de formação continuada deve se basear "na reflexão deliberativa e na pesquisa-ação, mediante as quais os professores elaboram suas próprias soluções em relação aos problemas práticos com que se deparam" (IMBERNÓN, 2010, p. 87).

Assim, para o autor, pensar sobre a prática não deveria ser uma ação restrita aos espaços das instituições formadoras nos quais os professores realizam cursos de formação continuada, mas acontecer também nos espaços do cotidiano escolar, nas reuniões coletivas com a presença do grupo gestor da escola e na interação entre os professores numa constante busca por respostas às diferentes situações relacionadas às 


\section{REVISTA ELETRÔNICA \\ DA GRADUAÇÃO/PÓS-GRADUAÇÃO EM EDUCAÇÃO UFG/REJ}

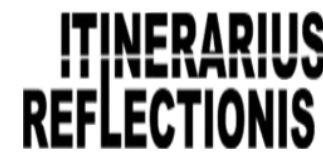

ISSN. 1807-9342

Volume 14, N. 2, 2018

dificuldades de aprendizagem. O professor assume, assim, uma postura de investigador de sua própria prática e este exercício de pesquisador lhe permite propor soluções afinadas com os problemas encontrados.

\section{OS SABERES DOCENTES E O RACIOCÍNIO GEOGRÁFICO}

A construção dos saberes do professor de geografia é um processo que envolve os conhecimentos da geografia acadêmica, a didática da geografia e a própria geografia escolar. A geografia escolar vem se constituindo com elementos da geografia acadêmica, da autonomia presente nas práticas escolares, da legislação vigente - como a Nova Lei de Diretrizes e Bases da Educação e as Diretrizes Curriculares Nacionais -, dos livros didáticos e das concepções dos professores sobre a geografia e sobre como ensiná-la (CAVALCANTI, 2012). Inclui-se a Base Nacional Comum Curricular, em processo final de elaboração, como documento norteador dos conteúdos que serão definidos no currículo da Educação Básica e que aponta para a não obrigatoriedade de disciplinas como Geografia e História na etapa do Ensino Médio.

Assim, faz-se necessário pensar o curso de formação de professores de geografia levando-se em consideração a importância de se conhecer a história do pensamento geográfico, os fundamentos epistemológicos desta ciência, as discussões teóricometodológicas, assim como estratégias didáticas como mecanismo para decodificar a linguagem da geografia para estudantes de diferentes faixas etárias. Tais fundamentos coadunam-se com o desenvolvimento do raciocínio geográfico do estudante da educação básica, mas para que o desenvolvimento de tal competência aconteça é mister evidenciar a importância da geografia escolar para que esta seja problematizada nos cursos de formação, como eixo transversal às disciplinas ministradas no curso (CAVALCANTI, 2012). De outra forma, para a autora, o aluno tornar-se-á um profissional acrítico, que reproduz o conhecimento dos livros didáticos e apostilas sem questioná-los, ou que leciona conteúdos sem que de fato o raciocínio desenvolvido seja pelo viés da espacialidade, no sentido de promover um raciocínio essencialmente geográfico.

Essa forma socialmente dominante da geografia escolar e universitária, na medida em que ela enuncia uma nomenclatura e que 


\section{REVISTA ELETRÔNICA \\ DA GRADUAÇÃO/PÓS-GRADUAÇÃO EM EDUCAÇÃO UFG/REJ}

inculca elementos de conhecimento enumerado, sem ligação entre si (o relevo, o clima, a vegetação, a população...) tem o resultado não só de mascarar a trama política de tudo aquilo que se refere ao espaço, mas também de impor, implicitamente que não é preciso, senão memória" (LACOSTE, 2011, p. 32-33).

A memória é um elemento importante para o desenvolvimento do raciocínio geográfico, mas restringir-se a ela não é suficiente. São necessárias conexões de elementos presentes em diferentes escalas com o propósito de conduzir o aluno a um entendimento do mundo; dado que os fenômenos nele acontecem simultaneamente, não se pode compreendê-lo partindo de uma perspectiva linear.

Ao transmitir informações ou conteúdos de forma isolada para os alunos, reforça-se o ensino tradicional pois

trabalhar com informações desconectadas de explicações mais amplas, colabora com a transmissão de ideias que professam a manutenção dentro de regras estabelecidas, ao invés de valorizar o conhecimento de cada um resgatando o conhecimento cientificamente produzido e dando-lhe um significado social (CALLAI, 2001, p. 140).

Os conhecimentos que os alunos devem adquirir a partir da geografia escolar devem ser trabalhados como conteúdos vivos, pulsantes, repletos de sentidos e significados, e não como tópicos desvencilhados da realidade, que o aluno deve descrever e, então, memorizar.

Desde 1976, com Yves Lacoste, a crítica à geografia descritiva já permeava as reflexões sobre o rumo que a geografia escolar e a geografia universitária estavam tomando. Apesar de, mais de vinte anos depois, muitos outros geógrafos como Callai (2001), Cavalcanti (2012) e Leite (2002) renovarem as críticas ao ensino da geografia enquanto um ensino pautado exclusivamente na memorização, parece ainda haver um abismo entre as escolas básicas e os seus docentes e as pesquisas desenvolvidas no âmbito da universidade.

Por conseguinte, a geografia é uma ciência que possui todos os elementos para desvendar a realidade que se apresenta mascarada, e que um olhar ingênuo e sem curiosidade não é capaz de descortinar. Quando são criadas condições favoráveis para o exercício da imaginação, do pensar sem amarras e do respeito à curiosidade do estudante (FREIRE, 2004), permite-se a apropriação e compreensão de determinado conteúdo e o desenvolvimento da capacidade de criação do aluno. Muitas pesquisas 


\section{REVISTA ELETRÔNICA \\ DA GRADUAÇÃO/PÓS-GRADUAÇÃO EM EDUCAÇÃO UFG/REJ}

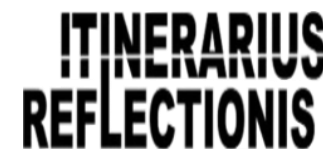

ISSN. 1807-9342

Volume 14, N. 2, 2018

vêm sendo desenvolvidas nesta direção, a partir de autores como Callai (2012), Castellar (2012) e Castrogiovanni (2012), pois, sem curiosidade e criação, alunos reproduzem mecanicamente o que lhes foi ensinado e não avançam no sentido de fazer proposições para os problemas que se apresentam em seu cotidiano.

Logo, estabelecer relação com a realidade mais próxima do estudante é uma maneira de entender a geografia como uma ciência do presente que possui papel fundamental na formação crítica dos estudantes. Ao ser ensinada como ciência neutra ou a partir de uma metodologia que faz dela uma disciplina aparentemente inútil, sem conexão com a realidade, a geografia não cumpre o seu papel de desmascarar a ideologia dominante para que se realize uma intervenção no mundo por meio da educação (FREIRE, 2004). Portanto, se queremos uma intervenção que produza implicações positivas, a geografia que se ensina nas escolas dos ensinos fundamental e médio deve pautar-se nos princípios de uma educação que produza inquietações. Assim sendo, a mudança deve acontecer na perspectiva de uma geografia que cumpra o seu papel de formar pessoas capazes de transformar, porque entenderam que o espaço é produzido socialmente por uma sociedade que contraria, resiste e dialeticamente adequa-se às metamorfoses desse espaço. É preciso formar professores que deem conta desse desafio.

O professor de geografia é o responsável por instrumentalizar o educando com as ferramentas que lhe permitirão ler o mundo num processo de descortinamento, na medida em que uma outra realidade lhe vai sendo mostrada e lhe fornece elementos para que possa construir possíveis respostas às inquietações.

Para Cavalcanti (2012, p.36), o papel da geografia é "explicitar a espacialidade das práticas sociais", o que significa fornecer elementos para que o aluno interprete o mundo com a lente da Geografia. Cabe ao professor de geografia transformar uma notícia num fato geográfico, ajudando primeiramente o aluno a atribuir-lhe significação e, em seguida, mostrando as relações entre as pessoas e o ambiente (SELBACH, 2010). Entretanto, muitos professores de geografia parecem não estar preparados para conduzir a aula pelo viés da geografia sem desvirtuar a discussão para um discurso que um professor de outra área do conhecimento poderia fazer: um debate sobre fatos atuais que não acionam no estudante mecanismos que lhe permitam visualizar a realidade sob um olhar espacial ou pela lente da geografia. 


\section{REVISTA ELETRÔNICA \\ DA GRADUAÇÃO/PÓS-GRADUAÇÃO EM EDUCAÇÃO UFG/REJ}

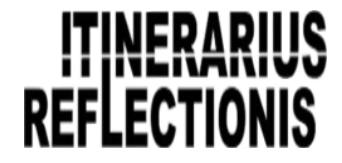

ISSN. 1807-9342

Volume 14, N. 2, 2018

Desta forma, "muitos professores de Geografia se perdem e não trabalham a apropriação do texto pelos alunos [...] sem inserir a informação em uma teia de relações que materializam o texto geográfico" (SELBACH, 2010, p. 62). Nesta circunstância, os fatos são analisados como notícias e não como ponto de partida para a compreensão do espaço como algo continuamente produzido pela sociedade; sem que os atores envolvidos na notícia e a repercussão da mesma - no arranjo espacial local, regional ou mundial -, sejam considerados. A consequência disto é uma superficialidade na leitura dos fenômenos ao invés de um aprofundamento por meio de uma interlocução do fenômeno noticiado com os conteúdos previstos no currículo. Relacionar as notícias atuais aos conteúdos da geografia é parte do trabalho docente de conduzir o estudante ao desenvolvimento do raciocínio geográfico.

Para Silva (2014, p.35), “o uso da expressão raciocínio geográfico implica pensar o ensino de Geografia na perspectiva de entendimento e compreensão da realidade, num movimento de superação da Geografia, pautada por descrições e enumerações" e que demanda, por parte do professor, domínio dos saberes da ciência e dos saberes pedagógicos. Ao indicar elementos constitutivos do raciocínio geográfico, a autora considerou os pressupostos teórico-metodológicos da Geografia, bem como a complexidade inerente ao processo de aprendizagem.

Assim, o conceito de raciocínio geográfico parte do pressuposto de que a experiência/vivência do uso do espaço, que começa com o nascimento bem como as descobertas a partir do engatinhar, passando para os primeiros passos até os trajetos feitos a pé ou os longos percursos de carro ou avião, são condicionantes para as noções espaciais que serão desenvolvidas nos anos iniciais do ensino fundamental. A importância das experiências vivenciadas e de como estas interferem no modo como o cérebro processa noções espaciais mais complexas são parte da teoria sociocultural de Vygotski (2014), mas, dadas as limitações do presente trabalho, não serão aqui aprofundadas.

Alguns mecanismos que acionam processos de aprendizagem são: a memória das experiências vivenciadas, a imaginação a respeito do que ainda não se tem conhecimento e o processo de elaboração de um novo conceito, dentre outros (VYGOTSKI, 2014). Tais mecanismos são cada vez mais influenciados pela utilização cotidiana das novas tecnologias. Para o autor (2014), os processos de pensamento se dão 


\section{REVISTA ELETRÔNICA \\ DA GRADUAÇÃO/PÓS-GRADUAÇÃO EM EDUCAÇÃO UFG/REJ}

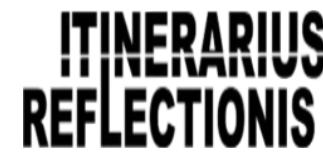

ISSN. 1807-9342

Volume 14, N. 2, 2018

pela historicidade, pelo constante vir a ser marcado pela cultura e que produzem o desenvolvimento individual que é fruto da nossa relação com o mundo. Essa relação com o mundo, expressada nas falas dos estudantes sobre suas experiências, configura-se elemento que pode ser explorado utilizando-se de metodologias que acionem tais experiências e, consequentemente, mecanismos como a memória, a imaginação e a formação de um novo conceito. A conversão de conteúdos do currículo em contação de histórias, marcadas por uma narrativa que enfatize as transformações provocadas no espaço geográfico e as categorias chaves da geografia, por exemplo, promove um esforço da mente em lembrar e ao mesmo tempo imaginar, mecanismos essenciais no processo de aprendizagem, segundo Vygotski (2014). Da mesma maneira, lançar mão de montagem de quebra-cabeças cuja imagem seja um mapa e outros jogos que estimulem o raciocínio alteram o modo como se dá a compreensão destes conteúdos. Outra estratégia são as bolas de brinquedo transformadas em globos terrestres, que permitem representar a Terra tridimensionalmente: o conteúdo torna-se concreto e facilita o processo de construção de conceitos sobre as linhas imaginárias e a associação destas com fatores climáticos, por exemplo. A utilização do desenho, como elemento da alfabetização cartográfica e do pensamento visual, permite explorar dificuldades de representação e de compreensão da realidade, o que favorece intervenções mais acertadas por parte do docente. Estas estratégias de aprendizagem são algumas possibilidades de favorecer o desenvolvimento do raciocínio geográfico e que dependerão de adequação, por parte do professor, conforme características das turmas/escolas/comunidade e das experiências desenvolvidas no espaço.

Neste sentido, o desenvolvimento do raciocínio geográfico está diretamente vinculado às experiências no espaço, acumuladas ao longo da vida. A evolução de tal raciocínio, por sua vez, está associada à aquisição de um conjunto de habilidades, construção de conceitos geográficos e desenvolvimento de competências. Ao elaborar reflexões na perspectiva do raciocínio geográfico, o aluno percebe o espaço tridimensionalmente e compreende os fenômenos na perspectiva da simultaneidade:

Simultaneamente, porque diferentes eventos ocorrem no espaço ao mesmo tempo, fato que exige um entendimento interescalar e multiescalar sobre determinado fenômeno, que só pode ser compreendido numa interface do lugar com o mundo; das experiências vividas às experiências mentalmente concebidas. 


\section{REVISTA ELETRÔNICA \\ DA GRADUAÇÃO/PÓS-GRADUAÇÃO EM EDUCAÇÃO UFG/REJ}

Tridimensionalmente, porque o mundo palpável possui três dimensões e ao estudar, por exemplo, uma paisagem ou um mapa cartográfico, é preciso decodificá-los numa lógica tridimensional, a partir das apreensões que são realizadas no percurso construído pelo educando em seu cotidiano, qual seja, o do uso do espaço (SILVA, 2017, p. 76).

As possibilidades de criar situações que favoreçam o desenvolvimento de tal raciocínio estão atreladas à formação inicial robusta que abarque os conhecimentos fundantes da geografia, bem como as estratégias didáticas citadas, necessárias à construção destes conhecimentos para estudantes de diferentes séries do ensino básico. Para tanto, uma disciplina que tivesse como escopo a didática específica da geografia e suas diferentes linguagens, como por exemplo a cartografia, permitiria que a formação inicial abarcasse elementos estruturantes do ofício do professor de geografia: a competência em traduzir o conhecimento acadêmico para a sala de aula e apropriação de estratégias em sejam utilizados os mais variados recursos didáticos disponíveis, para que a geografia escolar promova raciocínios complexos cujo viés seja o da espacialidade.

Pode-se sugerir que um dos desafios para se criar uma disciplina específica no campo da Geografia Escolar é a desvalorização dos cursos de licenciatura, reforçada com as reformas, em curso, que afetarão diretamente o ensino de Geografia para a educação básica. Contudo, uma disciplina que tratasse especificamente de metodologias de ensino de Geografia promoveria uma interface entre a geografia acadêmica e a geografia escolar e, para além, permitiria aos graduandos uma formação pautada pela importância da totalidade, no sentido de compreender que qualquer fenômeno possui dimensões física e humana, econômica e cultural, superando dicotomias e contribuindo para que o trabalho em sala de aula produzisse conhecimento necessário sobre a realidade do estudante, seu lugar, sempre em relação com o mundo.

\section{CONSIDERAÇÕES FINAIS}

A formação do professor de Geografia está atrelada a todos os desafios até aqui expostos, acrescidos das especificidades de uma ciência que deve ser responsável por formar profissionais aptos a tornar os seus alunos pessoas que consigam olhar o mundo pela lente da geografia; capazes de compreender que a sociedade produz o mundo 


\section{REVISTA ELETRÔNICA \\ DA GRADUAÇÃO/PÓS-GRADUAÇÃO EM EDUCAÇÃO UFG/REJ}

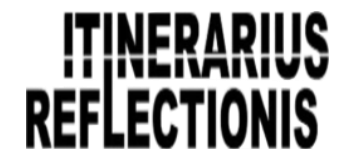

ISSN. 1807-9342

Volume 14, N. 2, 2018

visível e que há uma trama política, econômica e social implícita na paisagem e que a mesma precisa ser lida e compreendida.

Uma proposta para redimir a dicotomia entre a formação específica e a formação didática dos cursos de licenciatura é a inserção de uma didática específica da geografia nos currículos dos cursos de formação de professores com o objetivo de promover uma interlocução do currículo da licenciatura em geografia com o currículo da educação básica. Uma didática específica da geografia permitiria abordar ferramentas importantes para dinamizar o ensino de geografia para a educação básica, levando em consideração a linguagem cartográfica, a linguagem do desenho (pensamento visual), as experiências de uso do espaço vivenciadas pelo estudante, com a finalidade de construir uma metodologia de ensino aprendizagem que contemple os variados mecanismos de desenvolvimento do raciocínio geográfico.

Sem o arcabouço teórico da ciência geográfica acrescida da formação pedagógica voltada para as especificidades da geografia, a formação de professores de geografia seguirá incompleta. Apenas um professor bem formado, a partir de um currículo que contemple os processos de aprendizagem, terá condições de criar, a partir de suas aulas, condições efetivas de aprendizagem geográfica.

\section{REFERÊNCIAS}

CALLAI, Helena Copetti A formação do profissional da geografia. Ijuí: UnIjuí, 1999.

A geografia e a escola: muda a geografia? Muda o ensino? Terra Livre. São Paulo, p.133-152, 2001.

(org.). Educação Geográfica: Reflexão e Prática. Ijuí: Editora UnIjuí, 2011.

Estudar o lugar para compreender o mundo. In: CASTROGIOVANNI, Antonio

Carlos. Ensino de Geografia: práticas e textualizações no cotidiano. $10^{\mathrm{a}}$ Ed. Porto Alegre:

Editora Mediação, 2012.

CASTELLAR, Sonia. A psicologia genética e a aprendizagem no ensino de geografia. In: CASTELLAR, Sonia. Educação geográfica: teorias e práticas docentes. São Paulo: Contexto, 2012.

CASTROGIOVANNI, Antonio Carlos. Por que a Geografia pode não sertão interessante? In: CASTROGIOVANNI, Antonio Carlos. Ensino de Geografia: práticas e textualizações no cotidiano. 10ª Ed. Porto Alegre: Editora Mediação, 2012.

CAVALCANTI, Lana de Souza. O ensino de geografia na escola. Campinas, SP: Papirus, 2012. 


\section{REVISTA ELETRÔNICA \\ DA GRADUAÇÃO/PÓS-GRADUAÇÃO EM EDUCAÇÃO UFG/REJ}

\section{ITHERARIIUS REFLECTIONIS}

ISSN. 1807-9342

Volume 14, N. 2, 2018

FREIRE, Paulo. Pedagogia da Autonomia. São Paulo: Paz e Terra, 2004.

IMBÉRNON, Francisco. Formação docente e profissional: formar-se para a mudança e a incerteza. São Paulo: Cortez, 2010.

LACOSTE, Yves. A Geografia - isso serve, em primeiro lugar para fazer a guerra.

Campinas, São Paulo: Papirus, 2011.

LEITE, Cristina Maria Costa. Geografia no Ensino Fundamental. Universidade de Brasília/ Departamento de Geografia, Coleção Espaço e Geografia, Vol.5, N. ${ }^{\circ}$ 2, Gestão Urbana e Regional, Brasília: 2002.

PEREIRA, Diamantino. A dimensão pedagógica na formação do geógrafo. Terra Livre, vol 14, p. 41-50, jan-jul, 1999.

PERRENOUD, Philippe; THURLER, Monica Gather. As competências para ensinar no século XXI: a formação dos professores e o desafio da avaliação. Porto Alegre: Artmed, 2002.

SELBACH, Simone. Geografia e didática. Petrópolis: Vozes, 2010.

SILVA, Denise Mota Pereira. Raciocínio Geográfico e avaliação formativa: uma análise aplicada ao Ensino Médio. 162 p. Dissertação (Mestrado em Geografia). Universidade de Brasília. Instituto de Ciências Humanas, Departamento de Geografia, Programa de PósGraduação em Geografia. Brasília/DF, 2014.

SILVA, Denise Mota Pereira. Brasília: asas ao desenvolvimento do raciocínio geográfico. Revista do Instituto Histórico e Geográfico do Distrito Federal. Goiânia, p.75-82, 2017.

TARDIF, Maurice. Saberes docentes e formação profissional. 14ª Ed. Petrópolis, RJ: Vozes, 2012.

Vygotski, L. S. Obras Escogidas II: pensamiento y linguaje-conferencias sobre Psicologia. Madrid: Machado Libros, 2014. 